
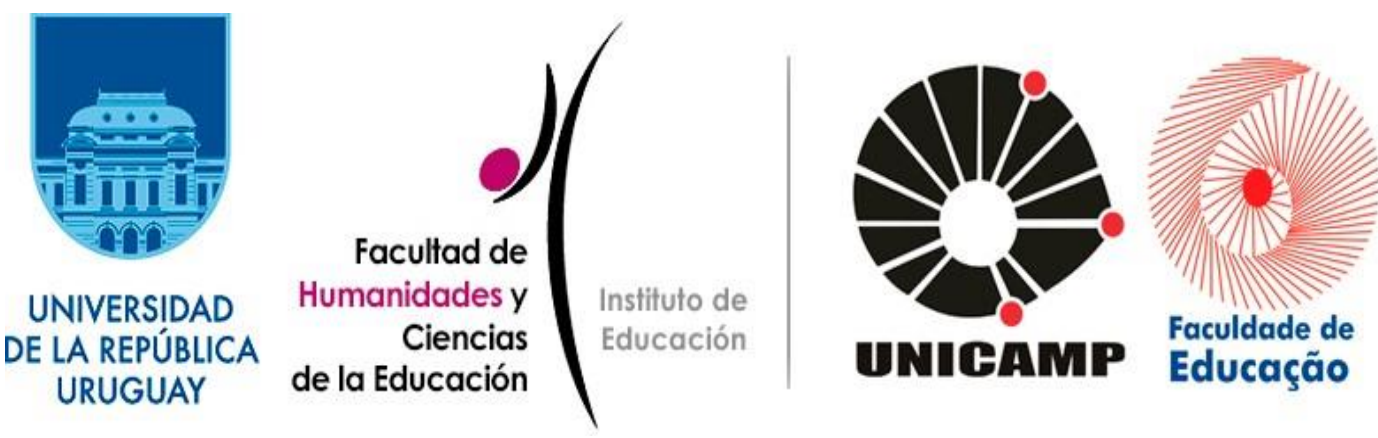

$$
\text { ARTÍCULO | ARTIGO }
$$

Fermentario V. 14, $\mathrm{N}^{\circ} 1(2020)$

ISSN 16886151

Instituto de Educación, Facultad de Humanidades y Ciencias de la Educación, Universidad de la República. www.fhuce.edu.uy

Faculdade de Educação, UNICAMP. www.fe.unicamp.br

\title{
Laicidad, dimensión religiosa y migraciones en el Uruguay
}

Secularism, spirituality and migration in Uruguay

\author{
Nelson Villarreal Durán ${ }^{1}$ \\ Michelle Carrère ${ }^{2}$
}

DOI: https://doi.org/10.47965/fermen.14.1.6

Recibido: $22 / 03 / 2020$

Aceptado: $22 / 05 / 2020$

\section{Resumen}

El fenómeno de la migración siempre fue parte de la realidad uruguaya, aunque de diversas maneras.

En los últimos diez años, el saldo migratorio pasó de negativo a positivo. A su vez, los perfiles y los orígenes de quienes deciden inmigrar a Uruguay han atravesado varios cambios.

\footnotetext{
${ }^{1}$ Nelson Villarreal Durán es licenciado en Filosofía, Diplomado en Efectividad para el Desarrollo y Ciencia Política. Docente G3 en Facultad de Derecho de la Universidad de la República. Integrante de la Red de Laicidad y Democracia, exsecretario de Derechos Humanos de Presidencia. Universidadnvd@gmail.com

${ }_{2}$ Michelle Carrère Seizer es licenciada en Ciencias de la Comunicación Social, Integrante del equipo del Ministerio de Educación y Cultura sobre Migración y Educación. michellecarrereseizer@gmail.com
} 
Con relación a la laicidad la migración plantea varios desafíos a la concepción de laicidad homogeneizante que ha predominado en nuestro país. En primer lugar, quienes vienen a Uruguay traen distintas culturas y religiones. En segundo lugar, incluso cuando la religión de los inmigrantes puede coincidir con alguna de las principales corrientes religiosas que hay en el Uruguay su forma de vivir y de expresar esa religiosidad puede ser diferente. A su vez, las formas de vivenciar en el espacio público y político difieren en distintos países y en distintas culturas, así como la interpretación que se le da a la laicidad. Esto puede generar desafíos a la laicidad.

El siguiente trabajo elabora sobre el vínculo histórico entre migración, religiosidad y laicidad y los desafíos e interrogantes que la migración reciente presenta a la laicidad entendida en el marco de un Estado de derecho preservando la igualdad social y tolerancia abriéndose a los aportes de la diversidad étnico/cultural.

Palabras clave: Migración, interculturalidad, diversidad cultural, cultura uruguaya, laicidad

\section{Abstract}

The migratory phenomenon has always been a part of uruguayan reality in different ways. In the last 10 years the migratory balance passed from negative to positive. At the same time, the profiles and origins of those who chose to immigrate to Uruguay have significantly changed.

In relation to secularism, immigration brings several challenges to the conception of homogenizing secularity that has predominated in the country. In the first place, those who come to Uruguay bring different cultures and religions. In second, even when immigrants' religion may coincide with one of the main religions present in the country, the ways of living and expressing spirituality may be different. At the same time, the ways of living public and political space differ between different countries and cultures, as well as the interpretation of secularism. This can produce challenges in secularism.

The following paper explores the historical relationship between migration, spirituality and secularism and the challenges and questions that recent migration presents to a secularism understood in the framework of the rule of law, preserving social equality and tolerance and embracing the contributions of ethnic and cultural diversity.

Keywords: Migration, interculturalism, cultural diversity, Uruguayan culture, secularism 


\section{Fundamentación ${ }^{3}$}

El fenómeno de la migración siempre fue parte de la realidad uruguaya, aunque de diversas maneras. En los últimos diez años, el saldo migratorio (la diferencia entre el número de personas que entra y sale del país), pasó de negativo a positivo. A su vez, los perfiles y los orígenes de quienes deciden migrar a Uruguay han atravesado varios cambios. Esto no solo tiene un efecto en lo socioeconómico sino en las subjetividades y espiritualidades en la medida en que generan un impacto diverso en la cultura.

Con relación a la laicidad la migración plantea varios desafíos a la concepción de laicidad homogeneizante que ha predominado en nuestro país. En primer lugar, quienes vienen a Uruguay traen distintas culturas y religiones. En segundo lugar, incluso cuando la religión de los inmigrantes puede coincidir con alguna de las principales corrientes religiosas que hay en el Uruguay su forma de vivir y de expresar esa religiosidad puede ser diferente. A su vez, las formas de vivenciar en el espacio público y político difieren en distintos países y en distintas culturas, así como la interpretación que se le da a la laicidad. Esto puede generar diversos desafíos.

Lo que se entiende como laicidad en el mundo no es un fenómeno unívoco, más allá que en Uruguay tenga una contundencia que define nuestra identidad, como han planteado la filósofa Andrea Díaz Genis (2018) y el sociólogo Néstor da Costa (Da Costa y Maronna, 2019) en la Red de Laicidad y Democracia de la Universidad de la República, que como concepto expresa el ethos sociocultural que caracteriza lo que se llama uruguayez en nuestro ser público.

Esa identidad se expresó como homogeneidad republicana en una etapa de la historia que dio sustento a nuestro ser democrático, pero hoy a partir de un nuevo fenómeno migratorio se comienza a reconocer la diversidad originante como la que deviene en el proceso actual, lo que sitúa una mayor densidad en lo que entendemos por laicidad.

Sin embargo, en estos procesos hay desafíos. En primer lugar, debemos preguntarnos: ¿cuáles son los límites de aquello que aceptamos en nombre de una laicidad inclusiva y una actitud de apertura hacia la diversidad cultural? Y, por consiguiente, ¿cómo actuar con prácticas religiosas y culturales que, en el marco de la inmigración, son defendidas desde la libertad religiosa o cultural pero que entran en conflicto con los fundamentos del Estado de derecho y por consiguiente con la laicidad?

\footnotetext{
${ }^{3}$ Presentado en las VIII Jornadas de Investigación, VII Jornadas de Extensión y VI Encuentro de Egresados y Maestrandos de la Facultad de Humanidades y Ciencias de la Educación de la Universidad de la República. Número de GT: 8 (La laicidad en disputa), octubre de 2019.
} 
A la hora de plantear estas y otras interrogantes sobre la temática identificamos la falta de investigaciones sobre la religiosidad de los migrantes recientes y su valoración de la laicidad. Por este motivo, nos propusimos realizar una serie de entrevistas a migrantes de diversas comunidades sobre su vivencia subjetiva.

\section{Supuestos teóricos. Repensando la laicidad}

En cuanto a la laicidad, como planteáramos en el foro de debate «Secularización y laicidad» en $2017^{4}$, se pueden identificar tres tendencias predominantes, todas centradas en la dimensión jurídica y política de la ciudadanía:

1) La laicidad entendida como laicismo que pone énfasis en el tema del Estado laico y la separación entre Estado e iglesias, autonomía del Estado frente a cualquier expresión religiosa.

2) La laicidad como inclusión, espacio de convergencia democrática en el que los diversos grupos y asociaciones religiosas pueden participar en la esfera pública.

3) La laicidad como punto medio entre las dos anteriores en el que se entiende como punto medio entre la exclusión de la separación entre Estado e Iglesias y la inclusión plena en la esfera pública. Este tercero excluido dibuja la laicidad como garante del espacio político y la ciudadanía.

La laicidad emerge como una forma de organización político-social que busca establecer la igualdad y la no discriminación, reconociendo a la diversidad y la pluralidad.

Es un instrumento jurídico-político-metodológico que las sociedades han creado, particularmente las occidentales, para que la pluralidad pueda ser vivida de manera dialógica. A los efectos de procesar los conflictos de sentidos, cosmovisiones y paradigmas.

Según Roberto Blancarte (2012) se puede hablar de la laicidad cuando existen tres elementos centrales en un determinado régimen: a) respeto de la libertad de conciencia; b) autonomía de lo político frente a lo religioso o ideológico totalizante (sea en política, sexualidad y en ciencias), y c) igualdad de las personas y sus asociaciones ante la ley, así como no discriminación.

La democracia moderna y la laicidad tienen elementos comunes de identidad: no puede haber una real laicidad sin una democracia constitucional y una democracia, para ser tal de manera cabal, requiere ser laica (Mclure y Taylor, 2011).

\footnotetext{
${ }^{4}$ Exposición de Nelson Villarreal en el marco del curso de Educación Permanente Religión y Política en la Modernidad Reflexiva, a cargo de José Kechichián en Facultad de Ciencias Sociales, Universidad de la República, 23 agosto de 2017.
} 
La laicidad no es la imposición absoluta de la voluntad de la mayoría a toda la población, sino que supone el respeto de los derechos humanos de todas las personas y en particular el respeto de los derechos de las minorías, sean estas religiosas, étnicas, de género, por preferencia sexual, etcétera. Los principios fundamentales de la laicidad se aplican a los debates que conciernen a las cuestiones relacionadas con: El cuerpo y la sexualidad, la enfermedad y la muerte, la emancipación de las mujeres, la educación de los/as niños/as, lo religioso y el espacio público, la ciencia, el poder del conocimiento y el acceso a la tecnología

\section{•¿Qué es la laicidad? Convivencia democrática en una sociedad pluralista}

Luego de los holocaustos, la caída del socialismo real y los procesos de cosificación en que ha devenido el liberalismo, la reemergencia neoconservadora emerge como desafío a la modernidad y el humanismo emancipador. Al decir de la teoría crítica se pone bajo sospecha la cuestión del sentido que da fundamento a la convivencia humana. El pacto social requiere tomar en cuenta otras dimensiones sin perder su secularidad para avanzar como humanidad.

Así mismo la Política es la centralidad de la vida de una sociedad democrática que sostener una convivencia pacífica.

En tal sentido el filósofo Jürgen Habermas plantea que el Estado liberal constitucional estaría llamado urgentemente a transformar «el potencial de significado de lo religioso adormecido por la irrupción secularizadora». Esta transformación tendría que ocurrir de tal forma que, a su vez, «el sentido religioso original... no pueda ser disminuido ni consumido desinflándose en el vacío». No se puede olvidar que el concepto de la dignidad humana tiene su origen en la tradición judeocristiana entre otros aportes de la humanidad (las tradiciones indígenas, musulmanas, africanas y orientales también aportan al concepto de dignidad humana que deben ser visualizadas en una sociedad democrática) (citado por Villarreal, 2014).

La cuestión es cómo y dónde se juega este movimiento de mutuo reconocimiento entre el Estado, lo público y lo religioso. En rigor este movimiento no es más que el despliegue dinámico de lo que se llama el Estado liberal democrático y el humanismo de la modernidad. Y lo propio de este despliegue es lógicamente el diálogo, pues ¿qué otra cosa sino diálogo es el movimiento de mutuo acercamiento, de mutua valoración y reconocimiento? Pero tal diálogo, entonces, ha de implicar la presencia de todos; de todos los actores de cada una de ambas partes que se reconocen. Esto podría constituir la buscada neutralidad del Estado, tan necesaria para la convivencia. 


\section{Complejización de las sociedades actuales}

Hoy el Estado se ve jaqueado por la racionalidad instrumental en su relación con subjetividades diversas. Esto tensiona tanto la ampliación de derechos, la visibilización de creencias, como la reemergencia de posiciones de irracionalidad en el marco de la convivencia social. Se constata la fragmentación del pacto social y la reemergencia del fundamentalismo religioso entre otras formas reactivas al cambio civilizatorio que se ha acelerado por lo tecnológico y la desestructuración de los paradigmas integradores de la modernidad. Pierde capacidad la Política como expresión subjetiva e institucional para dar sentido a las sociedades en relatos ideológico-culturales y por tanto la democracia como convivencia de lo plural se ve impactada.

La relación ciencia-tecnología se disocia en parte de los procesos de distribución y apropiación crítica que instaló como utopía la modernidad dura, que manifiesta la contradicción del acceso igualitario y autónomo a la acumulación de conocimiento de la humanidad

Más allá de la crisis de las ideologías o paradigmas integradores del siglo XX, que quitan sustento al relato de la modernidad como progresividad, la perspectiva secular de la Política como medio para la convivencia instaló el horizonte de la construcción acumulativa de los derechos humanos, como son el respeto a la diversidad y la tolerancia que se transforman en punto de convergencia y sustento de sociedades humanistas, a la vez que democráticas y republicanas

La modernidad en occidente desde la razón, seculariza valores inspirados en la fe judeocristiana que emergen como fundamentos de la consolidación de la democracia moderna, implica un desafío a la filosofía política y del derecho como las bases morales prepolíticas del Estado liberal moderno (Villarreal, 2014).

La laicidad como espacio de neutralidad que pauta la esfera de lo público, donde el Estado es garante del proyecto común conlleva una tensión en la construcción de ciertos relatos que se relegan al espacio de lo privado para consolidar igualdad. En ese sentido el ideal republicano para evitar la desigualdad excluye la diferencia y diversidad que implican las creencias. En la democracia la pluralidad es también pública y reclama de distinción entre el Estado, lo público, la comunidad social y las personas. La igualdad y la diferencia pueden ser conciliables.

Si la cristiandad y los estados confesionales anulaban la autonomía de la política, la sociedad y la subjetividad, el secularismo y laicismo instalado como ideología hegemónica en sus versiones más extremas supuso en algunos casos desconocer la integralidad del fenómeno humano. La reducción de 
lo religioso a un estadio privado, fantasioso y hasta enfermizo que supuestamente quedaría en el pasado no fue tal.

La realidad fue otra y por un lado la recuperación de la autonomía del Estado y las políticas consolidaron la democracia, a la vez que los sentidos que movilizan a las personas y sociedades, sean en lo religioso, estético o ideológico vuelven a pesar en los motivos para su visión del mundo, su sensibilidad y racionalidad configurando el sustento para comprender también la convivencia en otros planos.

\section{Planteará Habermas}

En la conciencia pública de una sociedad post-secular se refleja, ante todo, una intuición normativa que tiene consecuencias para el trato político entre ciudadanos creyentes y ciudadanos no creyentes. En la «sociedad postsecular» termina imponiéndose la convicción de que «la modernización de la conciencia pública» acaba abrazando por igual a las mentalidades religiosas y a las mentalidades mundanas (pese a las diferencias) y cambia a ambas reflexivamente. Pues ambas partes, con tal de que entiendan en común la secularización de la sociedad como un proceso de aprendizaje, pueden hacer su contribución a temas controvertidos en el espacio público, y entonces, también, tomarse mutuamente en serio por razones cognitivas (Villarreal, 2014).

\section{Migración y religiones ayer y hoy}

Es desde esta complejización de la laicidad que abordamos las transformaciones subjetivas que ha atravesado Uruguay (Achugar y Caetano, 1992) y que adquieren una connotación y visibilización distinta desde el fenómeno migratorio a lo largo de su historia.

Más allá de la imagen de Uruguay de ser un país poco religioso en lo público, hay expresiones de religiosidad popular que tan arraigadas que también tienen su lugar dentro del relato de la identidad uruguaya, la gran mayoría con origen en las migraciones (Geymonat y Sánchez, 1996). ${ }^{5}$

A su vez, la separación de la Iglesia del Estado y característica de Uruguay como un país laico afianzada en el batllismo no evitaron que grupos religiosos y creyentes de religiones diversas elijan

\footnotetext{
${ }^{5}$ Un claro ejemplo es el aporte de la migración italiana a las expresiones de catolicismo popular uruguayo como ser la devoción a San Roque en Colonia que data de la segunda mitad del siglo XIX; la Virgen de las Flores en La Floresta, y San Cono, este último es el de mayor presencia. La colonia italiana que se había establecido en Florida a finales del siglo XIX comenzó la devoción como cumplimiento a una promesa: al ser un gran porcentaje de los habitantes oriundos de la aldea Diano-Teggiano, lugar donde es originario el santo, le prometieron a San Cono que si superaban las penurias económicas que atravesaron al llegar, le construirían una capilla en su honor. Al ser en aquel momento la religión católica la religión oficial, consiguieron que se les diera un terreno para este fin.
} 
migrar a Uruguay, en algunos casos, escapando de la persecución en su país de origen. De hecho, en ocasiones, esta característica resultó un atractivo para algunos colectivos (Aguiar y Arocena, 2007). ${ }^{6}$

Una nueva subjetividad y biopolítica emerge en los años sesenta en Uruguay como resultado de la desagregación del modelo secular que había generado el batllismo. Tanto los sectores populares como contestatarios no se identificarán con la misma cosmovisión hegemónica que dejaba claro el límite entre lo público y lo privado. Tanto la crisis socioeconómica como la dictadura producirán un fenómeno de exilio y migración masivo. Este hecho sitúa al Uruguay como expulsor y no receptor de migración, hasta la primera década del siglo XXI. A la vez se da una evolución de la laicidad en relación con la estructura cultural y el vínculo con el fenómeno religioso.

La pérdida del espacio democrático en lo público generará un redescubrir del espacio privado como lugar político y de sentido. Un ejemplo es que fragua bajo la dictadura una interacción entre lo religioso y lo político (el video documental Fe en la Resistencia ${ }^{7}$ refleja la relación entre los militantes de izquierda y las corrientes religiosas ante un Estado que se hacía autoritario). Salidos de la dictadura y en los noventa adquiere otra dimensión, que expresa el estado de la subjetividad como la relación en cómo se ejerce la política y los sustentos que requiere para sostener compromisos, dando una nueva relación a religión y política. Biopolítica (Foucault, 1976) que muestra diversos hechos tanto en lo cotidiano como en lo social e institucional que trastocan la tradicional forma de relación entre lo religioso y el ser político de la sociedad y el Estado. Lo religioso ya no estará más relegado a lo privado y se muestran otras dimensiones que se entrecruzan.

\footnotetext{
${ }^{6}$ A principios de 1900, cuando se intensifica la migración de judíos, además de la política de puertas abiertas, se destaca la «temprana separación de la Iglesia y el Estado; la laicidad, gratuidad y obligatoriedad de la enseñanza pública» como algunos de los factores que hacían de Uruguay un destino atractivo. Durante la Segunda Guerra Mundial la población judía continuó aumentando, la gran mayoría venían de Europa central buscando salvar sus vidas de la persecución de los nazis. Las facilidades que brindó Uruguay no evitaron que sufrieran discriminación, ya que Uruguay no estaba libre de pensamiento antisemita. Por otra parte, las dos comunidades rusas que se instalaron en el país migraron al país a causa de persecución religiosa. En 1913, llegaron al país trescientas familias provenientes de Rusia pertenecientes a la secta religiosa Nueva Israel, liderada por el patriarca Vasili Lubkov, al tener dificultades para practicar su religión en Rusia, donde eran perseguidos por el zar. La política de «puertas abiertas» de Uruguay y su interés por atraer colonias agrícolas hizo que Uruguay resultara un destino atractivo. Una vez llegadas a Uruguay, las familias se instalaron en el territorio que hoy constituye San Javier. Si bien la cultura rusa sigue teniendo mucha presencia, hoy en día, la dimensión religiosa no es tan relevante para las familias que habitan San Javier: luego de varias irregularidades, Lubkov fue denunciado a las autoridades, por lo que este debió regresar a Rusia, todo esto llevó al debilitamiento de la secta. Por otra parte, a pocos kilómetros de San Javier en 1966 se instaló la Colonia Ofir. Esta fue conformada por 15 familias que provenían de Paraná Brasil. A allí habían llegado luego de ser expulsadas de Rusia por ser rusos blancos y no comunistas y posteriormente de China. Hasta el día de hoy practican una variante ultraconservadora del cristianismo ortodoxo denominada Starovieri. Sus particulares reglas y costumbres - como su particular vestimenta, solamente casarse entre creyentes de su religión, la prohibición del acceso a la televisión, radio y prensa - y el hecho que muchos no manejan el español, ha llevado a que, a pesar de estar en el territorio hace más de cincuenta años, se encuentren aislados del resto de la población del país. 7 https://www.youtube.com/watch?v=0GIw8ECGbSM
} 
Es en este contexto de cambios de subjetividades y cosmovisiones que remitían a paradigmas integradores que se encuentra en disputa el Estado Laico en el marco de la globalización y las transformaciones de las subjetividades impactadas por los cambios acelerados como por la no total concreción de las pretensiones racionalistas de la modernidad.

Hoy en día, la vivencia religiosa también sigue atravesando la subjetividad de la población vinculada a la migración, a modo de ejemplo en la muestra Todos/as somos Uruguay. Todos/as somos migrantes elaborada por la Secretaría de Derechos Humanos de Presidencia, de los veinte testimonios que recogen historias de migración personales o familiares de diversas personas, tres hacen mención a lo religioso. A modo de ejemplo, Rafael Marmolejos de República Dominicana hizo especial énfasis en este aspecto, él es diácono católico y junto con su esposa, que es catequista acompañan a los migrantes católicos en Uruguay y colaboran con la Parroquia de los Migrantes en Luis Alberto de Herrera, por otra parte Matilde Samisik, hija de migrantes polacos, cuenta como el resto de su familia que permaneció en Polonia murió a causa de la persecución de los Nazis, por otra parte, menciona que tiene un hijo rabino. Además de los testimonios que mencionan lo religioso, otro de ellos, de Breck Soto de Venezuela, destaca la laicidad de Uruguay como un aspecto favorable en su proceso migratorio, definiéndolo como un bendito país laico.

En la actualidad tanto la normativa vigente a nivel nacional, como la legislación internacional a la que Uruguay suscribe define a la migración como un derecho y establece la necesidad que los países de acogida den lugar a que la diversidad cultural se exprese. La Ley n. ${ }^{\circ} 18250$ (Ley de Migración) sostiene en su artículo 14 que «El Estado velará por el respeto de la identidad cultural de las personas migrantes y de sus familiares y fomentará que estas mantengan vínculos con sus Estados de origen» (Uruguay, 2008). En sintonía con esta perspectiva, el concepto de interculturalidad ha tomado mayor fuerza en los últimos años a la hora de hablar sobre el marco desde el cual se debería trabajar la integración,

«el concepto de interculturalismo intenta reflejar las relaciones entre los distintos
grupos culturales que conviven en un mismo espacio social. Además, no solo
reconoce la existencia de la diversidad cultural, sino que celebra el encuentro entre
culturas y promueve el diálogo entre ellas, lo cual no implica desconocer las
desiguales relaciones de poder sobre las que se construyen muchas de las pretendidas
diferencias culturales» (OIM, 2017).

En línea con esto, una laicidad incluyente, que dé lugar a que las diferentes culturas puedan expresarse, es un marco propicio para la integración y la convivencia pacífica, ya que da lugar a que las distintas culturas vivan su identidad cultural libremente, sin que una se imponga sobre la otra. 


\section{Nuevas subjetividades}

¿Qué formas toma la subjetividad en cuanto a lo religioso en los inmigrantes recientes? Al hacernos esta pregunta nos encontramos con varias dificultades a la hora de obtener respuesta. En primer lugar, si bien hay investigaciones sobre migración reciente que contemplan el aspecto religioso, especialmente en la vida social y cultural de algunas comunidades (Diconca, 2012), hasta el momento no hay investigaciones que detallen estadísticamente la pertenencia religiosa de quienes han llegado recientemente al país. Por otra parte, aún en el caso de contar con datos objetivos, que son necesarios para tener un panorama general, estos no serían suficientes para detallar la diversidad de sensibilidades religiosas: el fenómeno religioso toma distintas dimensiones y expresiones en diversos países, incluso cuando se observan los practicantes de una misma religión: por ejemplo, no es lo mismo la manera de vivir el catolicismo en República Dominicana, que en Polonia, que en Nigeria, que en Uruguay. En los distintos países entran en juego diferentes factores.

Para tener un mejor panorama de la vivencia religiosa de los migrantes recientes y contrastar la teoría con las experiencias subjetivas, nos propusimos realizar una serie de entrevistas a migrantes que practican una religión. Si bien esta muestra no es exhaustiva y las apreciaciones obtenidas no reflejan el espectro total de sensibilidades y religiosidades presentes en la población migrante, nos permiten salir de los preconceptos y contemplar la mirada del fenómeno desde la perspectiva de los propios protagonistas. A la hora de elegir a las personas a entrevistar buscamos reflejar tanto religiones que contaban con presencia en Uruguay, como religiones cuya presencia está directamente vinculada a la migración reciente.

Yoendris vino de Cuba hace dos años, es practicante de la religión yoruba, que define como un sincretismo entre religiones africanas y el catolicismo. Declara que a su llegada no le fue fácil continuar con su práctica religiosa, en primer lugar, porque la religión no tenía mucha presencia en el territorio, faltaba comunidad y un lugar específico donde reunirse; a su vez, en un principio varias personas que llegaron al país e intentaron establecer la religión lo hicieron con fines poco transparentes, utilizando la religión para enriquecerse, cosa prohibida por el culto. Hoy por hoy la situación ha mejorado sutilmente, se está intentando instalar una Asociación Yoruba en Uruguay con el apoyo de varias organizaciones (por ejemplo, Mundo Afro), pero aún falta compromiso en los miembros quienes no están unidos, falta el sentimiento de comunidad. Finalmente, sostiene que aún existe temor entre los practicantes, quienes ante el desconocimiento de su práctica religiosa por parte de la población sienten rechazo, en algunos casos en los que se los cataloga de tener una práctica diabólica. Otra dificultad que experimentan los creyentes es el encontrar un lugar donde realizar sus 
rituales, ya que una vez que comienzan un rito (que es muy llamativo, por lo que puede ser motivo de quejas de los vecinos), no se puede terminar, por este motivo han optado por realizarlos en lugares apartados, a las afueras de la ciudad. Siente que, en Cuba, donde considera que lo religioso tiene más presencia, los practicantes son más aceptados, ya que se conoce su práctica; en Uruguay, si bien él personalmente no vivió discriminación a causa de su religión, si es consciente que muchos la ocultan públicamente por miedo a ser discriminados o a que esto les repercuta negativamente en su trabajo. Finalmente, observó que en Uruguay la laicidad se vive de diferentes maneras: considera que varias instituciones del Estado como organizaciones de la sociedad civil están dando lugar a que las distintas religiones se expresen públicamente en su pluralidad, sin embargo, en el diálogo cotidiano percibe que las personas esperan que cada quien viva su religiosidad en el ámbito privado.

Argenis es venezolano, viven en Uruguay desde hace tres años y con su familia asisten a la parroquia Nuestra Señora de la Fundación en Lagomar. Tanto él como su familia concuerdan que vivir su fe en Uruguay no les resultó difícil, apenas llegaron y se incorporaron a la vida parroquial, relataron cómo, aunque no se presentaron como venezolanos, cuando el sacerdote de la comunidad los distinguió por su acento, enseguida les dio la bienvenida públicamente y los presentó al resto de los fieles.

Concuerdan en que si bien la celebración es la misma en cuanto al contenido en Venezuela se vive con más alegría, hay más música, y los jóvenes tienen más presencia. Sin embargo, de Uruguay rescatan que la figura del sacerdote es más cercana mientras que en Venezuela hay más distancia, la interacción se hace difícil. Por otra parte, resaltan que en Venezuela la religión tiene mayor presencia en el espacio público y en la manera de expresarse de las personas. En línea con esto, al ser consultados sobre si experimentaron discriminación, respondieron que no de manera explícita, pero sí sintieron la censura a la hora de manifestar su religiosidad, en especial los niños pequeños de la familia en la Escuela. Habituados a expresar su religiosidad de manera pública, decir gracias a Dios o solicitar la bendición a sus padres les resultaba natural; sin embargo, al expresarse de esta manera en la Escuela les llamaron la atención que Uruguay era un país laico, que aquí la gente no se hablaba de esa manera. En contraste, en Venezuela, el vínculo entre las instituciones religiosas y educativas es más estrecho. Incluso en centros públicos, al celebrarse las graduaciones, en Venezuela se ofrece a los estudiantes creyentes la posibilidad de realizar una misa de graduación (sin obligar a los que no creen), aquí sería impensable.

Tamara y Eduard llegaron a Montevideo desde Venezuela hace 18 meses con sus dos hijas, a principios de este año a su familia se les sumó Jorge, un joven de su comunidad religiosa que se define como su «hijo espiritual». Son pastores evangélicos e integran la comunidad de la iglesia Tierra de 
Bendiciones, ubicada en la calle Irlanda. Si bien antes de venir muchos les advirtieron que iban al país «más ateo de Latinoamérica», ellos no encontraron el ambiente hostil que les habían pronosticado, ni se sintieron discriminados por su fe, sino que encontraron respeto. Más allá de estos comentarios, lo cierto es que uno de los principales motivos por los que terminaron en Uruguay fue su religión. Antes habían pensado en migrar a República Dominicana y luego a Colombia, pero por diversos motivos no habían podido. Un día, Eduard estaba hablando con un Pastor uruguayo que había conocido en un viaje y explicándole la situación de la familia él les dijo que se vinieran a Uruguay. Todo se les dio de manera tan rápida (incluidos trámites, que pueden llegar a demorar muchos meses en Venezuela) que ambos afirman que «el Señor los quiso aquí». Resaltan que en los primeros meses su comunidad religiosa fue de gran ayuda. En comparación con Venezuela, sostienen que aquí la religiosidad se vive con menor intensidad, la parte musical es distinta, y también es difícil hablarle a la gente de Dios, no demuestran mucho interés. Si bien insisten en que nunca fueron discriminados, cuentan que un día en la celebración estaban tocando la batería un domingo a las 10 de la mañana y fue la policía de mala manera a decirles que habían recibido quejas de los vecinos. En contraste, les llamó la atención como en otras ocasiones, como en carnaval, sentían que hay más tolerancia. Finalmente comentaron que si bien en Uruguay sienten que las distintas religiones son respetadas, no es bien visto que se exprese la religiosidad públicamente. Como ejemplo, mencionaron que si quisieran hacer una marcha de la biblia por 18 de Julio seguramente habría resistencia, mientras que ven que se hacen marchas por «cualquier otra cosa», por las temáticas de género, diversidad sexual, etc., y que les gustaría sentirse con el mismo permiso para expresarse.

Más allá de sus diferencias entre los testimonios, todos coinciden en que se sintieron bien recibidos en Uruguay y en general se percibieron respetados por sus diferencias culturales y religiosas. Sin embargo, encontraron que no es bien visto expresar la religiosidad públicamente. Los tres relataron alguna experiencia, ya sea propia o de personas de su entorno, en que sintieron que la expresión de la religiosidad fue de alguna forma censurada: en el trabajo, en instituciones educativas, o a través de denuncias por ruidos molestos. Estas apreciaciones nos desafían a plantearnos de qué manera las nuevas subjetividades que trae la migración se vinculan con el espacio público, y si se deben establecer nuevos consensos o promover un cambio cultural de manera de favorecer espacios en los que se establezcan vínculos desde una perspectiva intercultural.

\section{Conclusiones, desafíos e interrogantes}

El reconocimiento, por un lado, que lo público no se agota en el Estado y por otro que hay dimensiones de lo humano que no solo quedan reducido a lo privado sino que se expresan 
socialmente, reclama de repensar la complejidad de lo que entendemos por laicidad y su rol en la consolidación de la secularidad que permite la convivencia con tolerancia y respeto a la pluralidad, diferencia y diversidad.

La laicidad se instala como expresión de la libertad y pluralidad de pensamiento, dando sustento al respeto y la tolerancia, lo que se transformó en garantía del desarrollo de los derechos humanos. Tendrá expresiones distintas, primero como confrontación con la institucionalidad religiosa y luego como garante de la pluralidad política ante las expresiones totalitarias y autoritarias de las ideologías políticas del siglo XX.

Sin embargo, la univocidad entre secularidad y laicidad de Estado adquirirá improntas distintas respecto a lo religioso en la perspectiva republicana que lo reducirá a la esfera privada que en lo democrático donde se reconocerá la pluralidad de las creencias en la vida social mientras no busquen trastocar la secularidad y laicidad del Estado.

Es desde la perspectiva democrática que se reconocerán la pluralidad de éticas para la convivencia asumiendo la complejización del pacto social que da cuenta de los Estados modernos para generar sinergias de humanismo desde la política y la garantía de derechos en tensión.

El Estado laico debe preservar la neutralidad como expresión republicana a la vez que reconocer la diversidad y fenómeno religioso no solo en las personas sino en la sociedad como expresión democrática. A la vez las tradiciones religiosas se ven desafiadas a reconocer y asumir los derechos y garantías comunes de un Estado Democrático que promueve la dignidad humana de las personas y colectivos.

Actualmente está el reto de redefinir viejas libertades e igualdades o que la sociedad reconozca nuevos derechos para la convivencia que es diversa y que suponen desafíos para la política pública, la educación y la relación Estado-sociedad.

El fenómeno de la migración plantea diversos desafíos y oportunidades a los estados receptores. Desafía la subjetividad hegemónica y replantea como se construye el nosotros desde el desafío de una otredad resultante tanto de la migración, la emigración y la población y colectivos no visibilizados en la historia. La uruguayez se replantea, se amplía la diversidad cultural existente en el territorio, nos lleva a repensar el imaginario cultural y desafía a pensar nuevas formas de integrar las distintas miradas, sensibilidades y expresiones culturales que trae. Este fenómeno ha existido desde el comienzo de la historia del Uruguay, sin embargo, los cambios en los perfiles migratorios y en el contexto nacional llevan a que su desafío sea permanente. Una laicidad incluyente resulta un marco 
propicio para gestionar el proceso de recepción de migrantes, de manera que, por un lado, en concordancia con la normativa nacional e internacional a la que Uruguay suscribe, se dé lugar a que expresen su identidad cultural y se favorezcan vínculos desde un enfoque intercultural, y por otro se limiten expresiones culturales que entran en conflicto con los fundamentos del Estado de derecho. Por este motivo, es necesario profundizar la producción académica que dé cuenta de las distintas identidades religiosas y sensibilidades de los migrantes recientes.

\section{Referencias bibliográficas}

Achugar, H. y Caetano, G. (1992). Identidad uruguaya: ¿mito, crisis o afirmación? Montevideo: Ediciones Trilce.

Aguiar, S. y Arocena, F. (2007). Multiculturalismo en el Uruguay. Montevideo: Ediciones Trilce.

Blancarte, R. J. (2012). ¿Cómo podemos medir la laicidad? Estudios Sociológicos, 30 (88), 233-247. Recuperado de https://www.jstor.org/stable/41410032?seq=1.

Da Costa, N. y Maronna, M. (2019). 100 años de laicidad en Uruguay. Debates y procesos (1934-2008). Montevideo: Planeta.

Díaz Genis, A. (2018). Sobre laicidad en disputa. Fermentario, 12.

Diconca, B. (Coord.) (2012). Caracterización de las nuevas corrientes migratorias en Uruguay Inmigrantes y retornados: acceso a derechos económicos, sociales y culturales. Montevideo: MIDES. Recuperado de http://eva.fhuce.edu.uy/pluginfile.php/40696/mod_resource/content/0/libromigrantes_versionweb_hb_1.pdf

Foucault, M. (1976). Derecho de muerte y poder sobre la vida. Ciudad de México: Fondo de Cultura Económica.

Geymonat, R. y Sánchez, A. (1996). La búsqueda de lo maravilloso. San Cono y otras devociones populares. Montevideo: Cal y Canto.

Maclure, J. y Taylor, Ch. (2011). Laicidad y libertad de conciencia. Madrid: Alianza Editorial.

Organización Internacional para las Migraciones (2017). Migraciones e interculturalidad. Guía para el desarrollo y fortalecimiento de habilidades en comunicación intercultural. [en línea]. Recuperado de https://publications.iom.int/es/books/migraciones-e-interculturalidad-guia-para-el-desarrollo-y-fortalecimientode-habilidades-en.

Uruguay (2008). Ley n. ${ }^{\circ}$ 18250. Ley de Migración. Recuperado de https://www.impo.com.uy/bases/leyes/18250-2008/76.

Villarreal, N. (2014). Las bases morales prepolíticas del Estado liberal (Algunos aspectos del diálogo sobre razón y fe entre el filósofo Jürgen Habermas y el teólogo Joseph Ratzinger). Revista de la Facultad de Derecho, (37). Recuperado de https://revista.fder.edu.uy/index.php/rfd/article/view/326. 